（20）今後必要吇強震観测：中規模孙儿大規模アレイの成要性

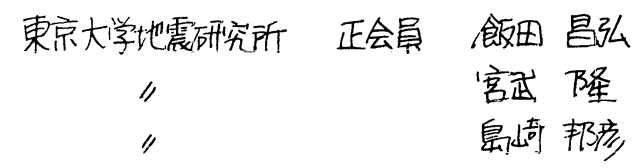

1。康

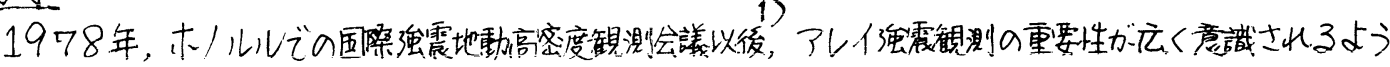

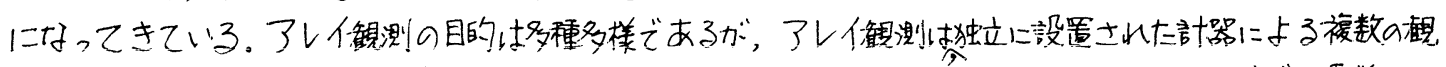
測と比較して，きわめて多くの情㛘を得る之とができるからである。しが，わガ国では，二れまで地震学のた

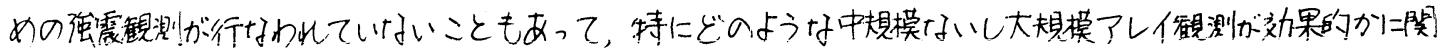
する証戴はほとんどナい。

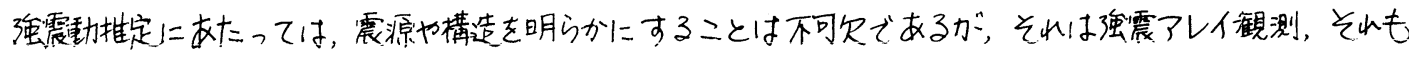

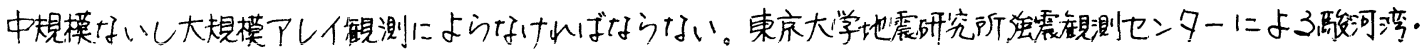

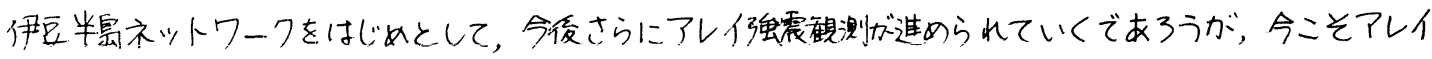

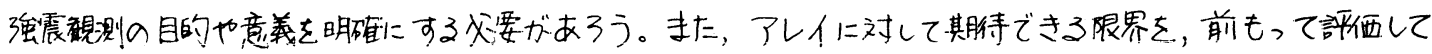
おくことも必要でろう。つまり，必要吇情報を明碓にし，最小限の努力で最大の情般を得ようという戦略的発 想をするべきだと思われるが、こうした試みはかつて椋されていない。その結果银制された労力は、データの公、 表吅整理に回されることが望ましい。

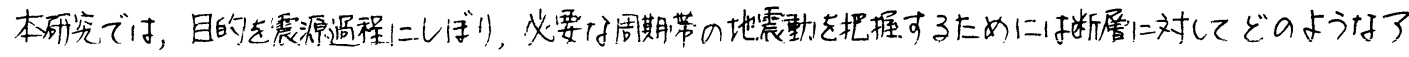

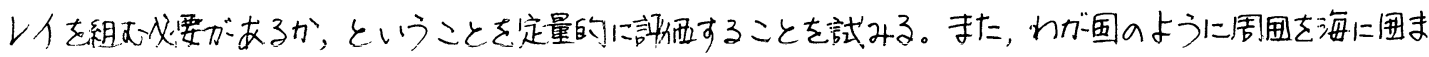

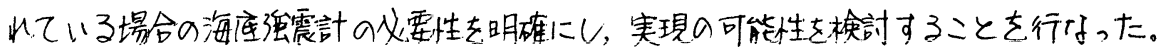

2。現在入㧧震観剘の周题点

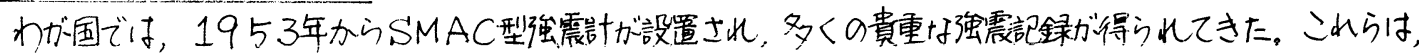
世界的にみてトップレベルにある、今日のわが国の利震設計の基整データとなっている。けれども，既存の千台 を越之る強震計は，地震学的に利用可能吇ネットワーフとしては全く機能し之孙い:うした点につき，太田。

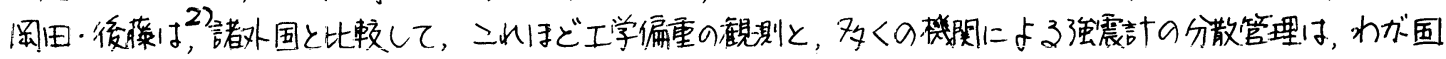
だけであると指摘している。このことは、データ公表がスムーズに行子かれないことにもつながリやすい。他方，

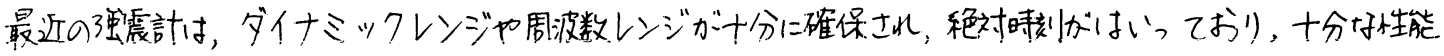
をもっている。このように計器の性能が向上すると、計器の配雷がそれだけ重要厂意味をもってくる。別マの機

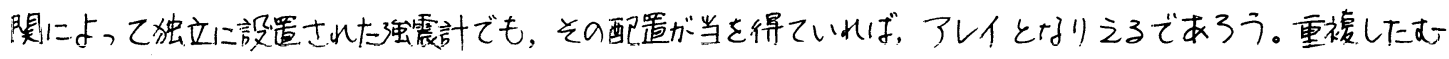
だ叮観测や，逆に䂓测次落がでてくることを防ぐには，わが国全体としてのアレイの配置計画が必要である。

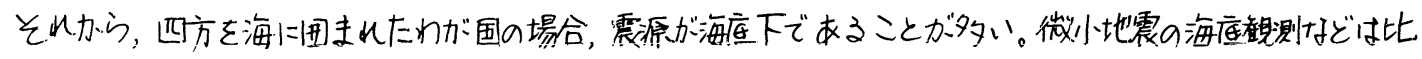

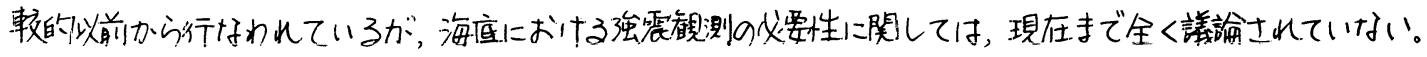

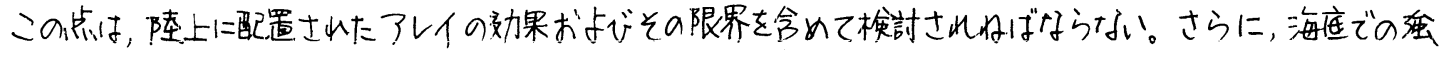
震钼测の必要性が大きい場合には，実際に海底に強震計を設置できるのかどうかも検討される必要がある。これ ウの検封を以下で行孙。 


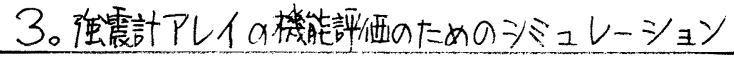

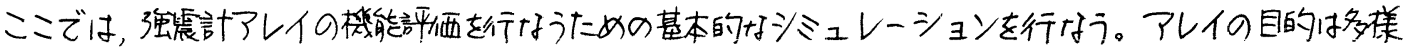

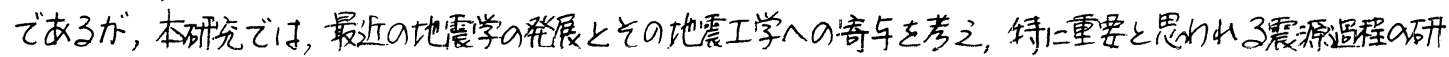
究に目的をしぼる。

3-1. 方法

震源遇程9研究でけ，钼测された地震波形汃断層面上での各点の運動をインバージョンによてて求める。も

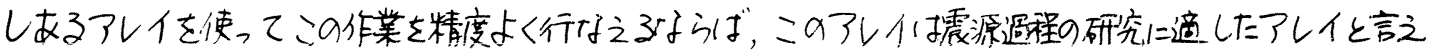

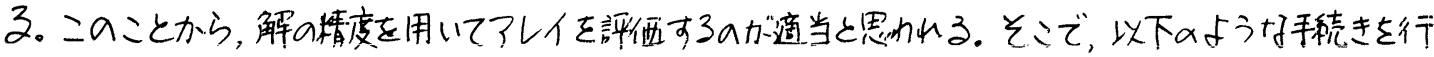

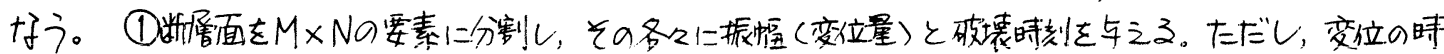

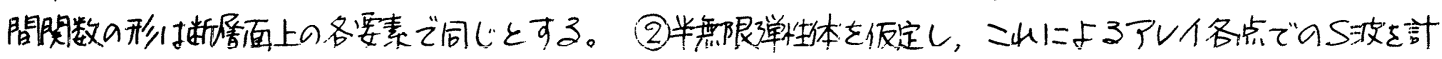

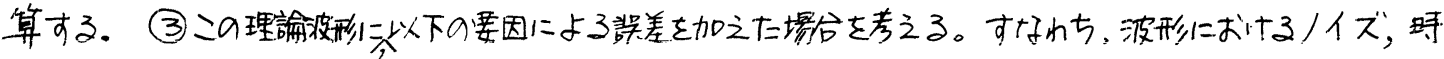

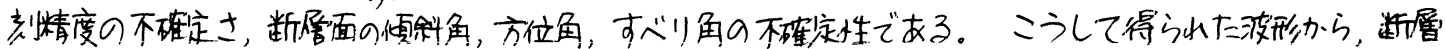

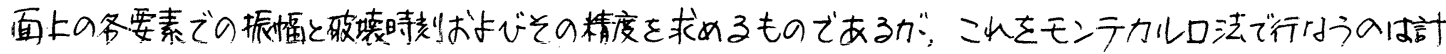

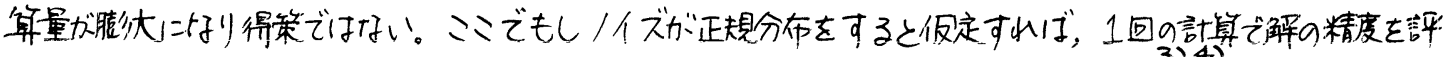

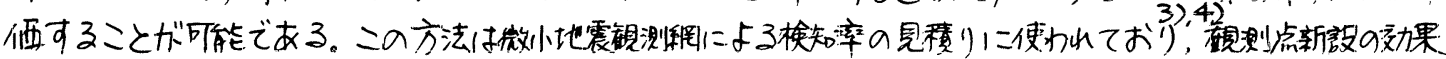
ナどに大きく役だっている。本研究では、これを震源遗程の助定に適用できるように改良してシミュレーション 行行方。

3-2. 計算例

ミンでは，いくかの例に基づいて，アレイの基本的なパメータと得られた解の精度、拼保を示し，必要と

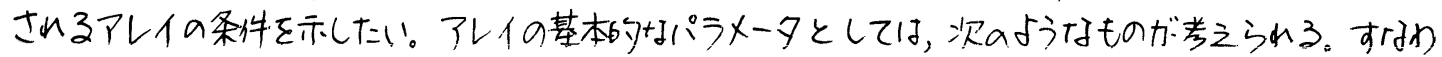

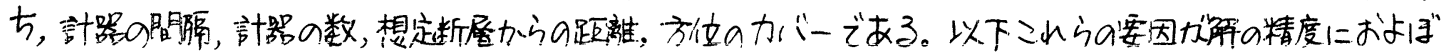

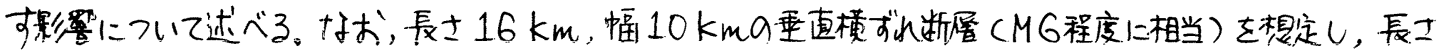
方向に8，幅方向に29計16㑑の要素儿分割する。各要素の大きさは，長士2 km，幅5 kmである，また，

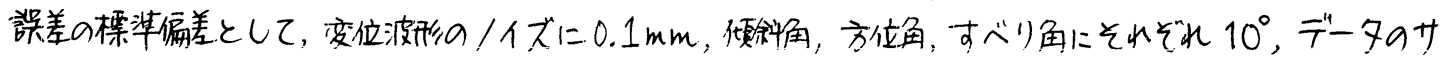

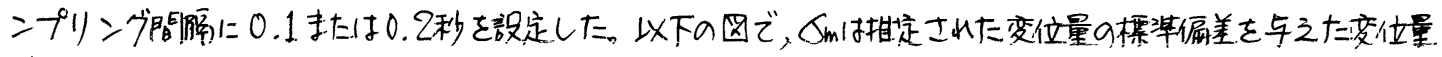
で割った值である。なお，2つの曲楾は上限䛧と下限値を示す。

(A)計哭，数: 䉼展を中心と(た判 $50 \mathrm{~km}$ (断展長さの3倍程度) の円を考之，その円周上に2〜９㑑の地震計を配置士せ，そのときの解の精 度を調べた。結果を図ー1に示す。少なくとも5点以上の钼制点が孙けば

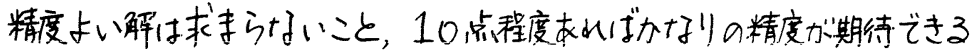
ことがわかる。

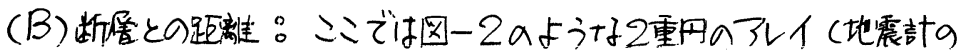

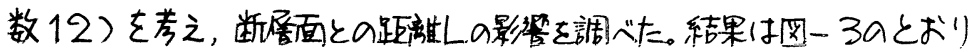

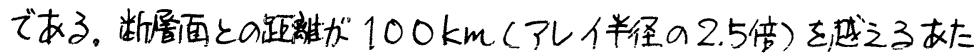
リから，解の精度が急激二悪くけっている。つまり，比較的密ではあっても， 1つのアレイだけで遠方の地震与解析するのは, 震源造程の研究に限ってい 之ぶ適当でな⿰い。

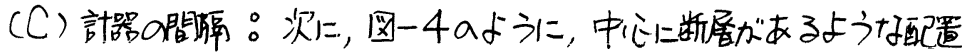
の16点から孙レイを考之た。解の精度は図一5のように坶る。れを

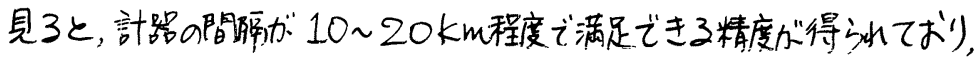

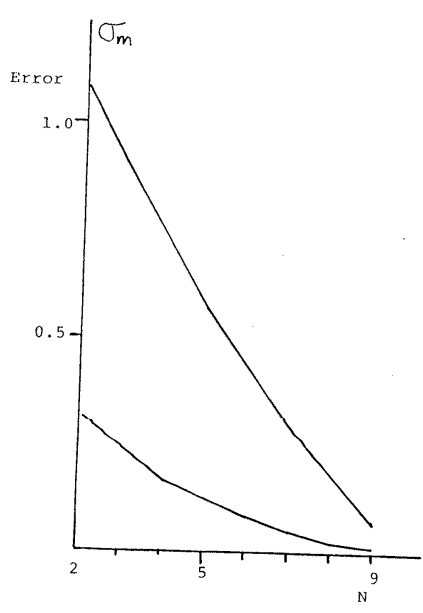

图一-1計器a数の影管 
少ナくとも断展の長さ程度の間膈に二計

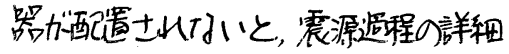

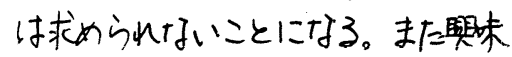

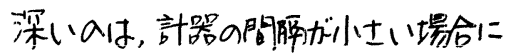
かえって解の精度が悪くなることでお る.フまりアアレイを断展のー部いの み密に設㯰したのでは不十分で，断啳 全体二分散さぜる必要があることであ 3.

(D) 方位のカバー: ミでは2例 の結果を示す。例1です、アしイが断 屏の片侧にのみ存在可子場合と，全体 を取り用たーように配置士れた境合との 遗いを比較し，例2(图一6)では， 海座下荻生した地震を想定し，片侧 (陸倒)にのみ锶测点力゙存在する徣合 と，海应强震計が1台追加士れた場合 とを比䡴している。例1では、アレイ に近い要素での遗いはとれはど見万れ ないが、最も遠い要素では触の精度は4倍もちガっている。実 噪例でも, 例之ば1979年のImperial Valley地震の解析で

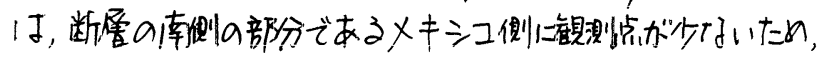

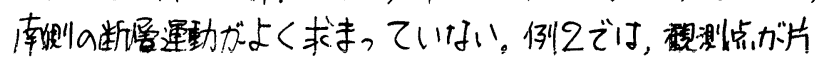
側、みにしか十い、場合には解の平均精度が0.8である、に榇し，

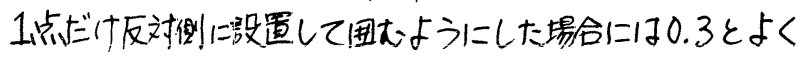

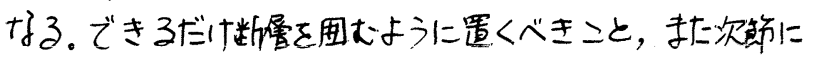
述べる海底强震計が不㰤であることを示している。

\section{4. 海底強震計}

以上のシミュレーショソンより，海底蛕震計設置动果がきわめて大

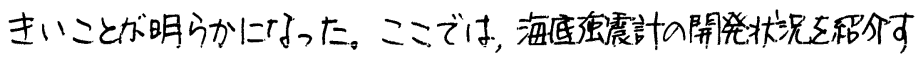
る。

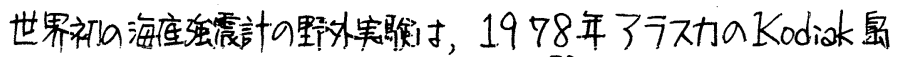

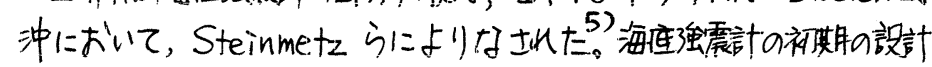

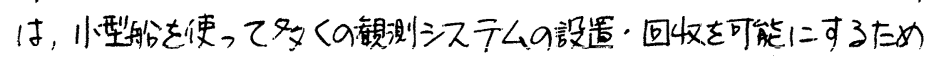

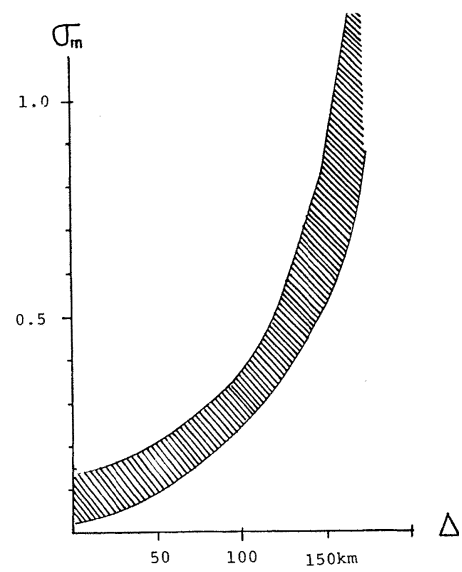

四-3 距離力影薌

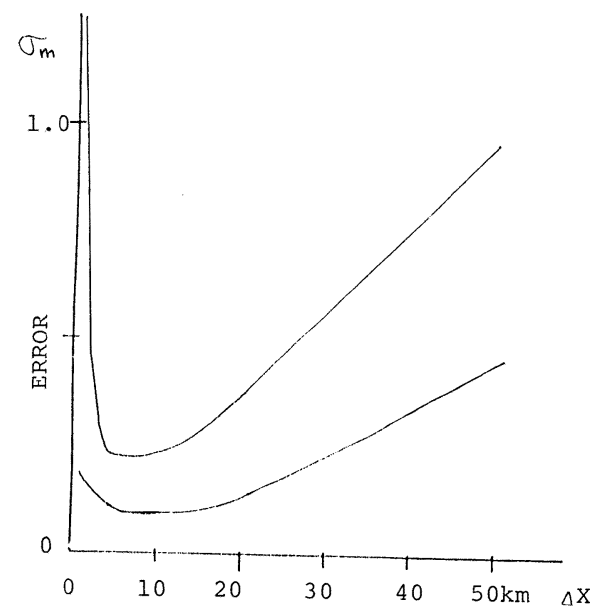

图一－5計器の間隔の影照

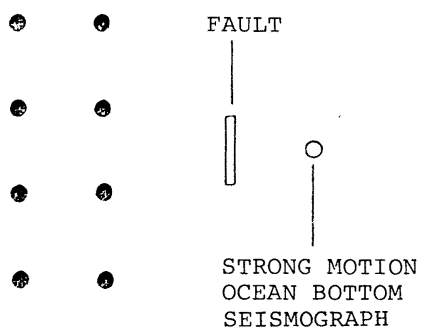

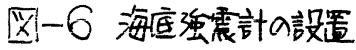

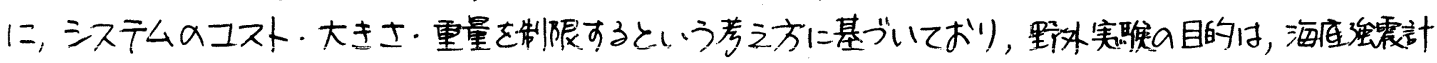

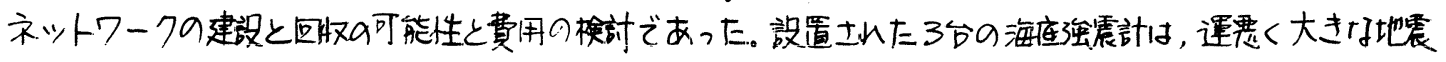

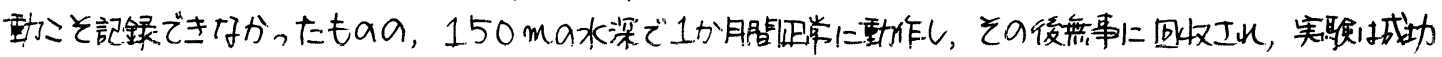

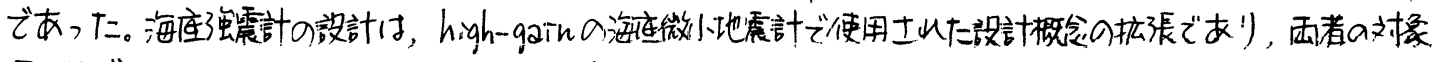

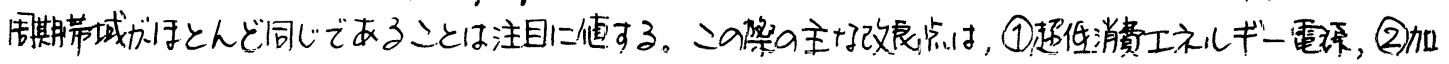




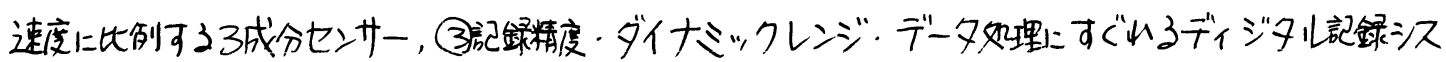

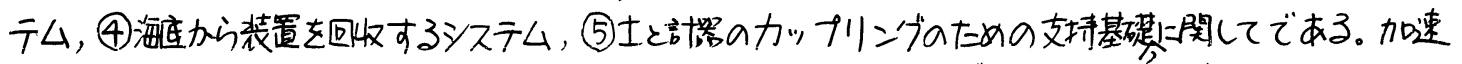

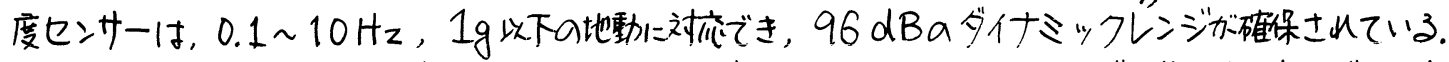

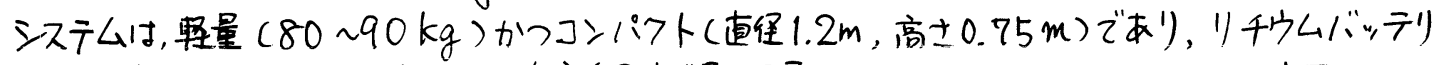

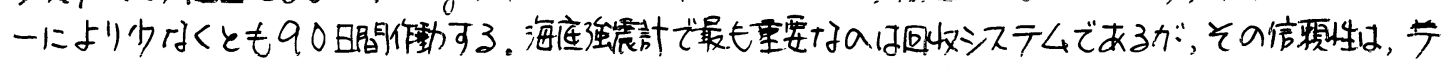

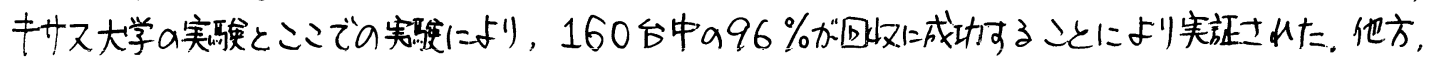

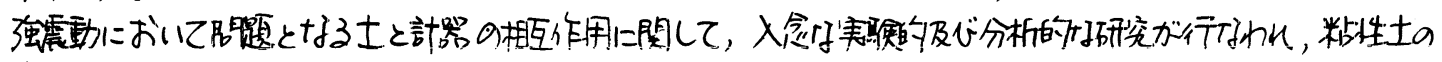

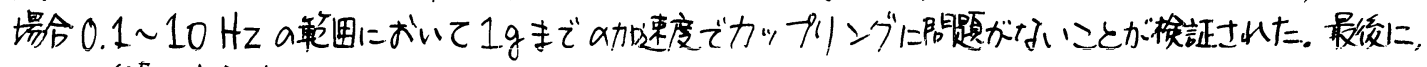

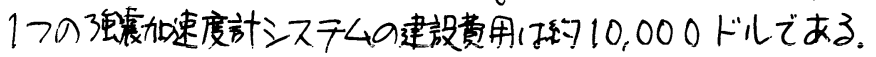

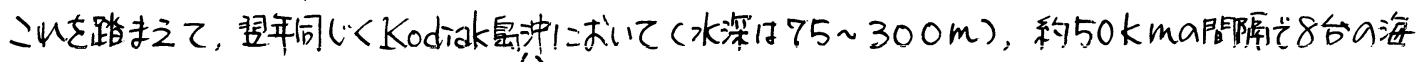

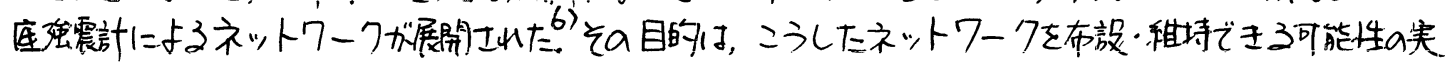

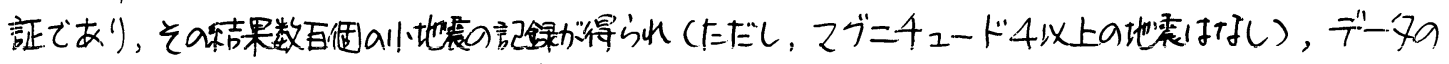

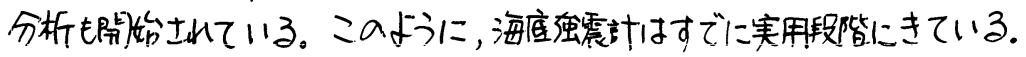

\section{5.まとめ}

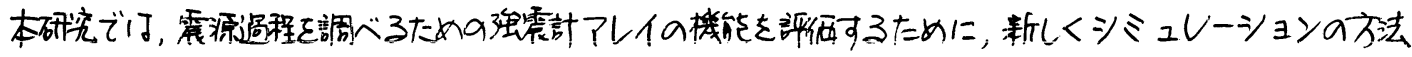

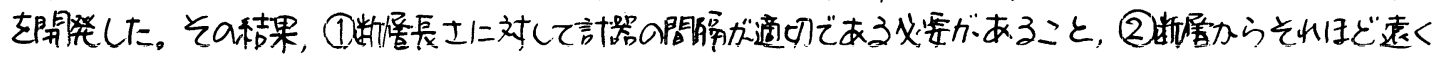

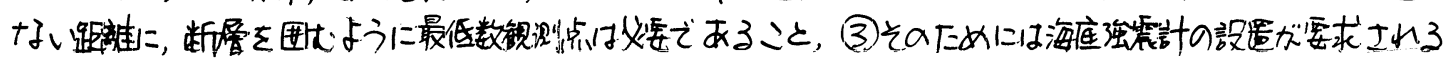

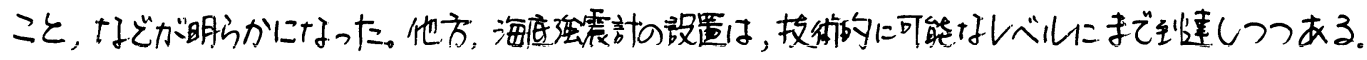

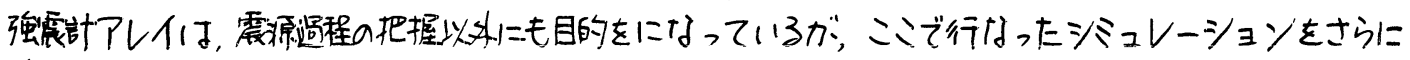

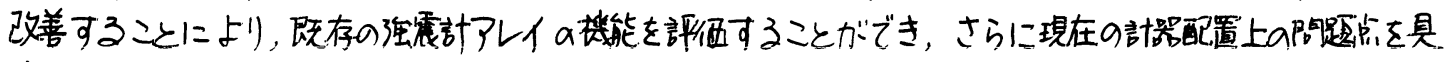

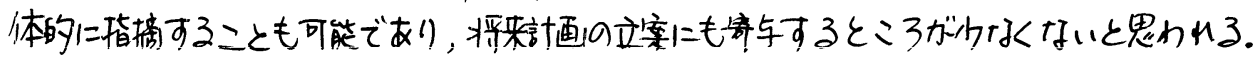

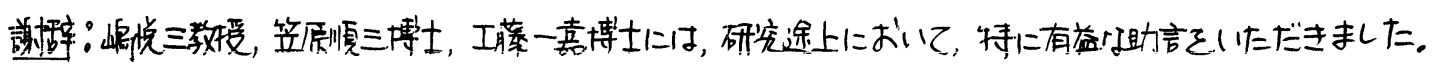
ミンに謝意を表します。

参㟥文献: 1) I wan,W.D. (Editor): Strong-motion earthquake instrument arrays, Froc. Internat. Workshop on Strong-motion, Earthq. Instrument Arrays, (Honolulu, Hawaii,) 1978.

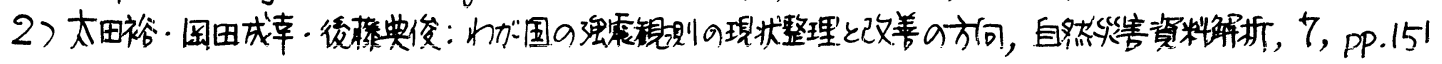
$\sim 169,1980$.

3) Peters, D.C. and R.S. Crosson: Application of prediction analysis to hypocenter determination using a local array, BSSA, Vol.62, pp, 775 788, 1972.

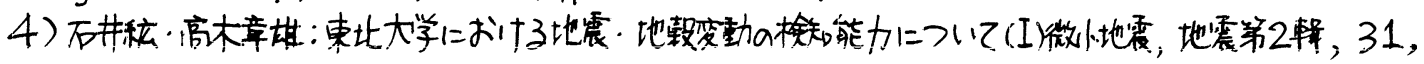
Pp. 287 , 298, 1998 .

5) Steinmetz, R.L., P.L.Donoho, J.D. Murff and G.V. Lathym : Soil coupling of a strong motion, ocean bottom seismometer, 11th, Offshore Technolugy Conference Proceedings, Vol.4, PP. 2235 2249, 1979.

6) Steinmetz, R.L., J.D. Murff, G. Latham, A.Roberts, P. Donoho, L. Babb and T. Eichel : Seismic. instrumentation of the Kodiak shelf, Marine Geotechnology, Vol.4, pp.193 221, 1981. 